\title{
Characteristics of patients vaccinated against influenza in physician offices versus pharmacies and predictors of vaccination location: a cross-sectional study
}

\author{
Nancy M. Waite PharmD, Suzanne M. Cadarette PhD, Michael A. Campitelli MPH, \\ Giulia P. Consiglio BSc, Sherilyn K.D. Houle PhD, Jeffrey C. Kwong MD MSc
}

\section{Abstract}

Background: Little is known about those vaccinated against influenza after pharmacists were added to the Ontario Universal Influenza Immunization Program, in 2012. Our aim was to identify characteristics of patients vaccinated against influenza and predictors of vaccination at a physician's office versus a community pharmacy.

Methods: We conducted a cross-sectional study of Ontario residents who had a record of receipt of an influenza vaccine between October and March in the 2013/14 and 2015/16 influenza seasons in Ontario using health administrative databases. We used Poisson regression models to estimate associations between baseline characteristics and the receipt of influenza vaccination in a community pharmacy. All analyses were stratified by age group ( $\leq 65 \mathrm{yr}$ or $\geq 66 \mathrm{yr}$ ).

Results: Overall, we found a 7.9\% decrease in vaccinations administered in 2015/16 (2 454 178) compared to $2013 / 14$ (2 677 278). The number of patients vaccinated in community pharmacies increased between the 2 periods (757 729 [28.3\%] in $2013 / 14 \mathrm{v}$. 859794 [35.0\%] in 2015/16). Living in nonurban areas or higher-income neighbourhoods, not identifying as an immigrant, not having a diagnosis of diabetes or hypertension, and receiving a pharmacist service on the same day as the vaccination were predictors of being vaccinated in a pharmacy, regardless of age group. Among patients aged 66 or more, those who had a hospital admission in the previous year were more likely to be vaccinated in a pharmacy than in a physician's office (adjusted incidence rate ratio [IRR] $1.08,95 \%$ confidence interval [Cl] 1.06-1.09), whereas those with higher annual medication costs were more likely to be vaccinated in a physician's office. The location of the previous season's vaccination predicted the current season's place of vaccination (age $\geq 66$ yr: physician's office: adjusted IRR 0.56 [95\% Cl 0.56-0.57], pharmacy: adjusted IRR 2.37 [95\% Cl 2.35-2.39]; age $\leq 65$ yr: physician's office: adjusted IRR 0.57 [95\% Cl 0.57-0.57], pharmacy: adjusted IRR 2.19 [95\% Cl 2.18-2.20]).

Interpretation: For the 2013/14 and 2015/16 influenza seasons, the influenza vaccine was administered more frequently in physician offices than in community pharmacies, but the proportion of patients vaccinated in community pharmacies increased between the 2 periods. Physicians and pharmacists can encourage patients to take advantage of the availability of influenza vaccines across various settings.

T accination is the most effective mechanism to prevent influenza and the resultant morbidity, mortality, work absenteeism and lost productivity. ${ }^{1-7}$ In 2000, Ontario introduced the Universal Influenza Immunization Program to provide influenza vaccine at no charge to all residents of the province aged 6 months or more through physicians' offices, public health clinics and workplaces. Although this strategy was effective in increasing overall influenza vaccine coverage, levels remained suboptimal. ${ }^{8-10}$ In an effort to further improve vaccine coverage, the Universal Influenza Immunization Program was expanded in October 2012 to allow injection-certified pharmacists in community pharmacies to administer influenza vaccines to Ontarians aged 5 years or more. Most Ontario residents live within a short distance of a pharmacy (91\% within
$5 \mathrm{~km}$ and $65 \%$ within $800 \mathrm{~m}),{ }^{11}$ and $51 \%$ visit a pharmacy at least once per month. ${ }^{12}$ In addition, pharmacists are available during extended evening and weekend hours, no appointments are necessary for many of their services, and they are available to people who do not have a primary care

Competing interests: Sherilyn Houle and Nancy Waite have received educational grants from Merck and Sanofi, and Sherilyn Houle received support for a graduate student trainee from Valneva Canada. No other competing interests were declared.

This article has been peer reviewed.

Correspondence to: Nancy Waite, nmwaite@uwaterloo.ca

CMAJ Open 2019. DOI:10.9778/cmajo.20180189 
provider. It was expected that the high degree of public access to trained community pharmacists would improve vaccine coverage. Indeed, similar policies have resulted in long-term absolute increases of $2.2 \%-7.6 \%$ in the number of adults aged 25-59 receiving influenza vaccine (no substantial change for those younger or older) in the United States. ${ }^{13-15}$ In Canada, people living in a province where influenza vaccine administration by pharmacists is allowed are $5 \%$ more likely to be vaccinated than those residing in provinces without this option. ${ }^{16}$

Although data exist on the impact on influenza vaccine coverage of pharmacists' being permitted to vaccinate, little research has been done to understand the types of patients who use this service, particularly in comparison to those vaccinated in physicians' offices. The objectives of the current study were to 1 ) characterize patients who were vaccinated in a community pharmacy or physician's office in Ontario and 2) identify predictors of receiving the vaccine in a community pharmacy or physician's office.

\section{Methods}

In this cross-sectional study, we identified all people who had a record in Ontario's population-based health administrative data of receipt of an influenza vaccine in community pharmacies or physician offices between October and March in the 2013/14 and 2015/16 influenza seasons ( 2 and 4 yr after implementation of the policy allowing pharmacists to vaccinate). We avoided the initial year after implementation, when the service was introduced across a limited number of pharmacies. At the time the study was conducted, the most recent health administrative data available were for the 2015/16 influenza season (there is a delay of about 18 mo between end of influenza season and data availability). The health administrative data sets were linked by means of unique encoded identifiers and analyzed at ICES. A description of the databases is provided in Appendix 1 (available at www.cmajopen. $\mathrm{ca} /$ content/7/2/E421/suppl/DC1). The ICES is an independent, nonprofit research institute whose legal status under Ontario's health information privacy law allows it to collect and analyze health care and demographic data, without consent, for health care system evaluation and improvement. If more than 1 vaccination was registered for the same patient within an influenza season, the earliest vaccination in the season was used as the patient's index date.

\section{Influenza vaccination data sources}

The Ontario Health Insurance Plan billing claims database captures influenza vaccines administered in physician offices by means of service provision codes and is validated. ${ }^{17} \mathrm{Com}-$ munity pharmacies bill for an influenza vaccination administration fee by processing a claim for that product to the government payer using its Drug Identification Number. This information is contained in the Ontario Drug Benefit database. The claim is associated with the pharmacy rather than a specific pharmacist; hence in this study we refer to vaccine administration in a community pharmacy (understanding that these were vaccines administered by community pharmacists). Appendix 2 (available at www.cmajopen.ca/content/7/2/E421/ suppl/DC1) provides the Ontario Health Insurance Plan service codes and Ontario Drug Benefit Drug Identification Numbers used for data extraction.

\section{Patient characteristics at time of vaccination}

We determined individual baseline characteristics relative to the index date (i.e., vaccination date). We used the Ontario Registered Persons Database to determine age, sex, Rurality Index of Ontario (RIO) score and neighbourhood income quintile of residence. The RIO score is a continuous measure of remoteness specific to Ontario that accounts for community size and travel time to basic and advanced medical centres. ${ }^{18}$ Patients were grouped into urban (RIO score 0-9), nonmajor urban (RIO score 10-39) and rural (RIO score $\geq 40$ ) residence. We obtained neighbourhood income quintile, which has been shown to be a reasonable proxy for socioeconomic status, ${ }^{19}$ by linking patient postal codes to Canadian census data. We used the Ontario portion of the Immigration, Refugees, and Citizenship Canada database to determine the landing date for immigrants to Ontario since 1985. Patients were classified as landing less than 5 years earlier, 5-9 years earlier, or 10 years or more earlier, or being a long-term resident.

We applied validated algorithms to the health care databases to determine selected diagnoses as of the time of vaccination that are associated with higher influenza morbidity and mortality: diabetes ${ }^{20}$ hypertension, ${ }^{21}$ chronic obstructive pulmonary disease, ${ }^{22}$ asthma, ${ }^{23}$ congestive heart failure ${ }^{24}$ and acute myocardial infarction. ${ }^{25} \mathrm{We}$ determined the incidence of cancer, except nonmelanoma skin cancers, using the Ontario Cancer Registry. ${ }^{26}$

We identified patients requiring a hospital admission, emergency department visit or home care visit in the previous year using the Discharge Abstract Database, National Ambulatory Care Reporting System and Home Care Database, respectively. Information regarding the number of physician office visits in the previous year and whether a patient received a periodic health examination was obtained from the Ontario Health Insurance Plan database. For patients aged 66 years or more, we used the Ontario Drug Benefit database to capture the number of unique prescription medications prescribed in the previous year, categorize their total cost $(<\$ 500, \$ 500-\$ 999, \$ 1000-\$ 1999, \$ 2000-\$ 2999, \$ 3000$ $\$ 3999, \geq \$ 4000)$ and flag whether the recipient had lowincome status. Because drug coverage in Ontario is universal only for adults aged 65 years or more, we measured prescription medications only for those aged 66 or more so that 1 year of data were available to calculate drug costs. However, since residents of all ages qualify for pharmacist services (MedsCheck Annual, MedsCheck Diabetes, MedsCheck at Home, Pharmaceutical Opinion Program and Pharmacy Smoking Cessation Program), ${ }^{27}$ we used the Ontario Drug Benefit database to assess receipt of these services in the entire study population in the year before (including up to the day of) vaccination. 


\section{Statistical analysis}

All analyses were stratified by age group ( $\leq 65 \mathrm{yr}$ or $\geq 66 \mathrm{yr}$ ). We summarized descriptive characteristics of patients as means or proportions. We used Poisson regression models, modified to analyze binary outcome data by incorporating a robust sandwich estimator to account for the misspecified error term, ${ }^{28}$ to estimate the adjusted incidence rate ratios (IRRs) between all of the measured baseline characteristics and receipt of influenza vaccination in a pharmacy. Because the outcome of receiving influenza vaccination from a pharmacist was relatively common, using standard logistic regression models to estimate odds ratios would have overestimated the measure of effect for each predictor. ${ }^{29} \mathrm{We}$ performed analyses using SAS Enterprise Guide version 9.3 (SAS Institute) and Stata version 13.1 (StataCorp).

\section{Ethics approval}

Ethics approval was obtained from the Research Ethics Board of the University of Waterloo.

\section{Results}

\section{Characteristics by age group and influenza season}

The total number of people recorded in the administrative data as vaccinated decreased by $7.9 \%$ between the $2013 / 14(n=$ $2677287)$ and 2015/16 $(n=2465178)$ influenza seasons, with a $14.2 \%$ decrease (1 691125 to 1450594 ) among those aged 65 years or less and a $2.9 \%$ increase (986 162 to 1014584 ) among those aged 66 or more. The characteristics of patients vaccinated in the 2 seasons by age group are summarized in Appendix 3 (available at www.cmajopen.ca/content/7/2/E421/ suppl/DC1). Few differences were seen between influenza seasons. A higher proportion of patients aged 66 or more than of those aged 65 or less lived in rural areas, were not recent immigrants, had several chronic diseases, had been vaccinated in the previous year in physicians' offices, had used health care services (including remunerated pharmacist services) in the previous year and were vaccinated in October.

\section{Characteristics by age group, influenza season and vaccine provider}

Table 1 presents information about those vaccinated by age group, influenza season and provider location. The proportion of patients vaccinated in physicians' offices was higher in both age groups and both influenza seasons but decreased between the $2013 / 14$ and $2015 / 16$ seasons, from $67.1 \%(n=$ $1135212)$ to $60.9 \%(n=883055)$ among those aged 65 or less, and from $79.5 \%(n=784346)$ to $71.2 \%(n=722329)$ among older patients. In the 2013/14 influenza season, $537155(47.3 \%)$ of those aged 65 or less vaccinated in a physician's office had been vaccinated in a physician's office the previous year, compared to $593096(75.6 \%)$ of those aged 66 or more; little change was seen in $2015 / 16$. In contrast, in both age groups, there was a marked increase between the 2013/14 and 2015/16 influenza seasons in the number vaccinated in a community pharmacy among those who had received the vaccine in a community pharmacy the previous year: $93868(16.9 \%)$ to $281121(49.5 \%)$ among those aged 65 or less, and 33207 (16.4\%) to 156379 (53.5\%) among those aged 66 or more.

\section{Predictors of vaccination location}

Figures 1 and 2 illustrate the IRRs for being vaccinated in physicians' offices compared to community pharmacies for patients aged 65 or less and 66 or more, respectively, for the 2015/16 influenza season. Living in smaller communities, living in the highest income quintile neighbourhoods and receiving a pharmacist service on the same day as the vaccination were all predictive of being vaccinated in a pharmacy, whereas identifying as an immigrant, prior vaccination in a physician's office and the presence of certain chronic health conditions (diabetes and hypertension) were associated with vaccination in a physician's office, regardless of age group. The location of the previous year's vaccination (whether physician's office or pharmacy) was a strong predictor of the vaccine provider for the current influenza season. Among patients aged 65 or less, hospital admission in the previous year predicted vaccination in a physician's office, and home care use or provision of a pharmaceutical service in the previous year predicted vaccination in a pharmacy. Among patients aged 66 or more, hospital admission in the previous year was predictive of vaccination in a pharmacy, whereas low-income status and higher annual medication costs were predictive of vaccination in a physician's office. Being vaccinated in November, December or January was predictive of vaccination in a pharmacy for all age groups, whereas, for those aged 66 or more, being vaccinated in March predicted vaccination in a physician's office.

Predictors of vaccination location for the 2013/14 influenza season were the same as for the 2015/16 season except that people aged 65 or less were more likely to be vaccinated in physician offices than in pharmacies in February and March, versus no association in 2015/16.

\section{Interpretation}

For the 2013/14 and 2015/16 influenza seasons, Ontarians were more likely to have received the influenza vaccine in a physician's office than in a community pharmacy, but there was an increase in the proportion of vaccines administered in a pharmacy between the 2 seasons. This likely reflects an increased awareness of the availability of this pharmacist service through public health, word-of-mouth and pharmacyspecific advertising. ${ }^{30,31}$

Over the past 20 years, pharmacists have been increasingly involved as partners with other health care professionals and public health departments in vaccination campaigns and as vaccinators themselves. ${ }^{32-35}$ Pharmacists can administer 1 , several or all vaccines across all US states and in 9 of the 10 Canadian provinces, with influenza vaccination permitted in all jurisdictions where pharmacists can vaccinate. ${ }^{36,37}$ In Ontario, pharmacists have been able to administer influenza vaccine since 2012, and this program was expanded in 2016 to include other, travel-related vaccines. 
Table 1 (part 1 of 2): Baseline characteristics of Ontario residents vaccinated in the 2013/14 and 2015/16 influenza seasons, by age group and location of vaccination provider

\begin{tabular}{|c|c|c|c|c|c|c|c|c|}
\hline \multirow[b]{3}{*}{ Characteristic } & \multicolumn{4}{|c|}{$\begin{array}{c}\text { 2013/14 influenza season; location of vaccination, } \\
\text { no. (\%) of patients* }\end{array}$} & \multicolumn{4}{|c|}{$\begin{array}{c}\text { 2015/16 influenza season, location of vaccination } \\
\text { no. (\%) of patients }{ }^{*}\end{array}$} \\
\hline & \multicolumn{2}{|c|}{ Age $\leq 65 \mathrm{yr}$} & \multicolumn{2}{|c|}{ Age $\geq 66 \mathrm{yr}$} & \multicolumn{2}{|c|}{ Age $\leq 65 \mathrm{yr}$} & \multicolumn{2}{|c|}{ Age $\geq 66 \mathrm{yr}$} \\
\hline & $\begin{array}{l}\text { Pharmacy } \\
n=555913\end{array}$ & $\begin{array}{c}\text { Physician's } \\
\text { office } \\
n=1135212\end{array}$ & $\begin{array}{l}\text { Pharmacy } \\
n=201816\end{array}$ & $\begin{array}{l}\text { Physician's } \\
\text { office } \\
n=784346\end{array}$ & $\begin{array}{l}\text { Pharmacy } \\
n=567539\end{array}$ & $\begin{array}{l}\text { Physician's } \\
\text { office } \\
n=883055\end{array}$ & $\begin{array}{l}\text { Pharmacy } \\
n=292255\end{array}$ & $\begin{array}{l}\text { Physician's } \\
\text { office } \\
n=722329\end{array}$ \\
\hline \multicolumn{9}{|l|}{ Demographic } \\
\hline $\begin{array}{l}\text { Age at } \\
\text { vaccination, yr, } \\
\text { mean } \pm S D\end{array}$ & $42.35 \pm 17.79$ & $40.02 \pm 20.46$ & $74.58 \pm 6.95$ & $75.99 \pm 7.20$ & $43.35 \pm 17.75$ & $40.73 \pm 20.41$ & $74.89 \pm 7.03$ & $76.09 \pm 7.27$ \\
\hline Female sex & $303116(54.5)$ & $627361(55.3)$ & $110136(54.6)$ & $428674(54.7)$ & 311438 (54.9) & $491171(55.6)$ & 159545 (54.6) & $392979(54.4)$ \\
\hline \multicolumn{9}{|c|}{ Rurality Index of Ontario score } \\
\hline Urban & $400929(72.1)$ & 900265 (79.3) & $128967(63.9)$ & $554548(70.7)$ & $407899(71.9)$ & $704958(79.8)$ & $182367(62.4)$ & $516802(71.5)$ \\
\hline $\begin{array}{l}\text { Nonmajor } \\
\text { urban }\end{array}$ & $128929(23.2)$ & $199741(17.6)$ & $58752(29.1)$ & $190992(24.4)$ & $132262(23.3)$ & $151809(17.2)$ & $88473(30.3)$ & $171354(23.7)$ \\
\hline Rural & $26055(4.7)$ & $35206(3.1)$ & $14097(7.0)$ & $38806(4.9)$ & $27378(4.8)$ & $26288(3.0)$ & $21415(7.3)$ & $34173(4.7)$ \\
\hline \multicolumn{9}{|c|}{ Neighbourhood income quintile } \\
\hline 1 (lowest) & $81645(14.7)$ & $215212(19.0)$ & 31307 (15.5) & $135463(17.3)$ & $84275(14.8)$ & $163833(18.6)$ & 44625 (15.3) & $122375(16.9)$ \\
\hline 2 & $94213(16.9)$ & $221639(19.5)$ & $37899(18.8)$ & $160329(20.4)$ & $96782(17.1)$ & $172238(19.5)$ & $53953(18.5)$ & $146153(20.2)$ \\
\hline 3 & $106402(19.1)$ & $227810(20.1)$ & $38281(19.0)$ & $156294(19.9)$ & $109083(19.2)$ & $177109(20.1)$ & $56336(19.3)$ & $144092(19.9)$ \\
\hline 4 & 125795 (22.6) & $239132(21.1)$ & $43712(21.7)$ & $163581(20.9)$ & $130181(22.9)$ & $191164(21.6)$ & $63825(21.8)$ & $154003(21.3)$ \\
\hline 5 (highest) & $147858(26.6)$ & $231419(20.4)$ & $50617(25.1)$ & $168679(21.5)$ & $147218(25.9)$ & $178711(20.2)$ & $73516(25.2)$ & 155706 (21.6) \\
\hline Low income & NA & NA & $19746(9.8)$ & $124216(15.8)$ & NA & NA & $26320(9.0)$ & $103719(14.4)$ \\
\hline \multicolumn{9}{|c|}{ Month of vaccination } \\
\hline October & $139731(25.1)$ & $440771(38.8)$ & 85260 (42.2) & $450054(57.4)$ & $99753(17.6)$ & $245473(27.8)$ & 82537 (28.2) & 309345 (42.8) \\
\hline November & $237952(42.8)$ & $418580(36.9)$ & $87501(43.4)$ & 262335 (33.4) & $343003(60.4)$ & $421753(47.8)$ & $172606(59.1)$ & 324576 (44.9) \\
\hline December & $59119(10.6)$ & $124597(11.0)$ & $13857(6.9)$ & $45878(5.8)$ & $95324(16.8)$ & $150302(17.0)$ & $29988(10.3)$ & $67038(9.3)$ \\
\hline January & $113432(20.4)$ & $129580(11.4)$ & $14556(7.2)$ & $22433(2.9)$ & $23256(4.1)$ & $47380(5.4)$ & $5913(2.0)$ & $16638(2.3)$ \\
\hline February & $4823(0.9)$ & $17492(1.5)$ & $569(0.3)$ & $2998(0.4)$ & $4808(0.8)$ & $13865(1.6)$ & $1029(0.4)$ & $3732(0.5)$ \\
\hline March & $856(0.2)$ & $4192(0.4)$ & $73(0.04)$ & $648(0.1)$ & $1395(0.2)$ & $4282(0.5)$ & $182(0.1)$ & $1000(0.1)$ \\
\hline \multicolumn{9}{|c|}{ Time since immigration, yr } \\
\hline Nonimmigrant & $494681(89.0)$ & 920309 (81.1) & $194136(96.2)$ & $716582(91.4)$ & $503451(88.7)$ & 719352 (81.5) & $279858(95.8)$ & $656326(90.9)$ \\
\hline$<5$ & $11552(2.1)$ & $40211(3.5)$ & $813(0.4)$ & $5469(0.7)$ & $6013(1.1)$ & $14291(1.6)$ & $600(0.2)$ & $2886(0.4)$ \\
\hline $5-9$ & $13002(2.3)$ & 44758 (3.9) & $1009(0.5)$ & $7729(1.0)$ & $13808(2.4)$ & $33501(3.8)$ & $1609(0.6)$ & $7656(1.1)$ \\
\hline$\geq 10$ & $36678(6.6)$ & $129934(11.4)$ & $5858(2.9)$ & $54566(7.0)$ & $44267(7.8)$ & 115911 (13.1) & $10188(3.5)$ & $55461(7.7)$ \\
\hline \multicolumn{9}{|l|}{ Comorbidity } \\
\hline Diabetes & $54584(9.8)$ & $168581(14.9)$ & $53936(26.7)$ & 264997 (33.8) & $62665(11.0)$ & $144678(16.4)$ & $81964(28.0)$ & $256396(35.5)$ \\
\hline Hypertension & $121978(21.9)$ & 308227 (27.2) & $140459(69.6)$ & $611099(77.9)$ & $130272(23.0)$ & $245319(27.8)$ & $204878(70.1)$ & 562473 (77.9) \\
\hline $\begin{array}{l}\text { Chronic } \\
\text { obstructive } \\
\text { pulmonary } \\
\text { disease }\end{array}$ & $9398(1.7)$ & $26884(2.4)$ & $17440(8.6)$ & $80492(10.3)$ & $10869(1.9)$ & $22807(2.6)$ & $25416(8.7)$ & 74029 (10.2) \\
\hline Asthma & 95131 (17.1) & $205529(18.1)$ & $25396(12.6)$ & $115787(14.8)$ & $99150(17.5)$ & $162238(18.4)$ & $38815(13.3)$ & $110502(15.3)$ \\
\hline $\begin{array}{l}\text { Congestive heart } \\
\text { failure }\end{array}$ & $4817(0.9)$ & $14809(1.3)$ & $15172(7.5)$ & $81333(10.4)$ & $5630(1.0)$ & $12601(1.4)$ & $22626(7.7)$ & $75666(10.5)$ \\
\hline $\begin{array}{l}\text { Acute myocardial } \\
\text { infarction }\end{array}$ & $5906(1.1)$ & $15179(1.3)$ & 10648 (5.3) & 45921 (5.9) & $6190(1.1)$ & $12374(1.4)$ & $15243(5.2)$ & $42086(5.8)$ \\
\hline Cancert & 18570 (3.3) & 40066 (3.5) & 30555 (15.1) & $121804(15.5)$ & $23249(4.1)$ & $37210(4.2)$ & 49457 (16.9) & 125255 (17.3) \\
\hline
\end{tabular}




\begin{tabular}{|c|c|c|c|c|c|c|c|c|}
\hline \multirow[b]{3}{*}{ Characteristic } & \multicolumn{4}{|c|}{$\begin{array}{c}2013 / 14 \text { influenza season; location of vaccination, } \\
\text { no. }(\%) \text { of patients }{ }^{*}\end{array}$} & \multicolumn{4}{|c|}{$\begin{array}{l}\text { 2015/16 influenza season, location of vaccination } \\
\text { no. (\%) of patients }{ }^{*}\end{array}$} \\
\hline & \multicolumn{2}{|c|}{ Age $\leq 65 \mathrm{yr}$} & \multicolumn{2}{|c|}{ Age $\geq 66$ yr } & \multicolumn{2}{|c|}{ Age $\leq 65 \mathrm{yr}$} & \multicolumn{2}{|c|}{ Age $\geq 66$ yr } \\
\hline & $\begin{array}{l}\text { Pharmacy } \\
n=555913\end{array}$ & $\begin{array}{l}\text { Physician's } \\
\text { office } \\
n=1135212\end{array}$ & $\begin{array}{l}\text { Pharmacy } \\
n=201816\end{array}$ & $\begin{array}{l}\text { Physician's } \\
\text { office } \\
n=784346\end{array}$ & $\begin{array}{l}\text { Pharmacy } \\
n=567539\end{array}$ & $\begin{array}{l}\text { Physician's } \\
\text { office } \\
n=883055\end{array}$ & $\begin{array}{l}\text { Pharmacy } \\
n=292255\end{array}$ & $\begin{array}{l}\text { Physician's } \\
\text { office } \\
n=722329\end{array}$ \\
\hline \multicolumn{9}{|c|}{ Use of health care services in previous year } \\
\hline $\begin{array}{l}\text { Influenza } \\
\text { vaccination in } \\
\text { physician's office }\end{array}$ & $132308(23.8)$ & $537155(47.3)$ & $92143(45.7)$ & $593096(75.6)$ & $91801(16.2)$ & $406390(46.0)$ & $87363(29.9)$ & $515454(71.4)$ \\
\hline $\begin{array}{l}\text { Influenza } \\
\text { vaccination in } \\
\text { community } \\
\text { pharmacy }\end{array}$ & 93868 (16.9) & $27364(2.4)$ & $33207(16.4)$ & $15944(2.0)$ & $281121(49.5)$ & $82324(9.3)$ & $156379(53.5)$ & $74034(10.2)$ \\
\hline $\begin{array}{l}\text { Hospital } \\
\text { admission }\end{array}$ & $23828(4.3)$ & $80604(7.1)$ & $19907(9.9)$ & $93660(11.9)$ & $24557(4.3)$ & $66061(7.5)$ & $28519(9.8)$ & $86168(11.9)$ \\
\hline $\begin{array}{l}\text { Emergency } \\
\text { department visit }\end{array}$ & $121020(21.8)$ & $268251(23.6)$ & $55602(27.6)$ & $227776(29.0)$ & $124111(21.9)$ & $213063(24.1)$ & $81315(27.8)$ & $214099(29.6)$ \\
\hline Home care & $14442(2.6)$ & $37564(3.3)$ & $23233(11.5)$ & $113629(14.5)$ & $15529(2.7)$ & 30896 (3.5) & $33233(11.4)$ & $104690(14.5)$ \\
\hline $\begin{array}{l}\text { No. of physician } \\
\text { office visits, mean } \\
\pm \text { SD }\end{array}$ & $8.43 \pm 12.25$ & $11.25 \pm 14.15$ & $14.30 \pm 15.83$ & $18.02 \pm 18.59$ & $8.83 \pm 12.86$ & $11.72 \pm 14.91$ & $14.17 \pm 15.67$ & $17.92 \pm 18.70$ \\
\hline $\begin{array}{l}\text { Periodic health } \\
\text { examination }\end{array}$ & $36291(6.5)$ & $79012(7.0)$ & $16748(8.3)$ & $66430(8.5)$ & $30867(5.4)$ & $45541(5.2)$ & $18865(6.5)$ & $43415(6.0)$ \\
\hline \multicolumn{9}{|c|}{ Use of pharmacy services in previous year } \\
\hline $\begin{array}{l}\text { No. of unique } \\
\text { prescription } \\
\text { medications, } \\
\text { mean } \pm \text { SD }\end{array}$ & NA & NA & $9.59 \pm 6.31$ & $10.27 \pm 6.94$ & NA & NA & $9.65 \pm 6.25$ & $10.18 \pm 6.90$ \\
\hline $\begin{array}{l}\text { Total cost of } \\
\text { prescription } \\
\text { medications, \$ }\end{array}$ & NA & NA & $\begin{array}{c}1373.28 \\
\pm 3764.67\end{array}$ & $\begin{array}{c}1596.94 \\
\pm 3343.26\end{array}$ & NA & NA & $\begin{array}{c}1446.58 \\
\pm 4113.70\end{array}$ & $\begin{array}{c}1655.59 \\
\pm 3731.92\end{array}$ \\
\hline$<500$ & NA & NA & $83738(41.5)$ & 260435 (33.2) & NA & NA & $125613(43.0)$ & $253066(35.0)$ \\
\hline $500-999$ & NA & NA & $42057(20.8)$ & $168536(21.5)$ & NA & NA & $60133(20.6)$ & $152874(21.2)$ \\
\hline 1000-1999 & NA & NA & $39853(19.7)$ & 177024 (22.6) & NA & NA & 53761 (18.4) & $153428(21.2)$ \\
\hline 2000-2999 & NA & NA & 17184 (8.5) & 82927 (10.6) & NA & $\mathrm{N} / \mathrm{A}$ & 24409 (8.4) & $74183(10.3)$ \\
\hline 3000-3999 & NA & NA & $7943(3.9)$ & 39555 (5.0) & NA & $\mathrm{N} / \mathrm{A}$ & 10827 (3.7) & $34964(4.8)$ \\
\hline$\geq 4000$ & NA & NA & $11041(5.5)$ & $55869(7.1)$ & NA & NA & $17512(6.0)$ & $53814(7.5)$ \\
\hline $\begin{array}{l}\text { Pharmacist } \\
\text { service }\end{array}$ & 59275 (10.7) & $122507(10.8)$ & 75413 (37.4) & $285434(36.4)$ & 63983 (11.3) & $102774(11.6)$ & $103553(35.4)$ & 260805 (36.1) \\
\hline $\begin{array}{l}\text { Pharmacist } \\
\text { service on day of } \\
\text { vaccination }\end{array}$ & $4238(0.8)$ & $3387(0.3)$ & $4848(2.4)$ & $6835(0.9)$ & $4760(0.8)$ & $2913(0.3)$ & $7117(2.4)$ & $6074(0.8)$ \\
\hline $\begin{array}{l}\text { Note: NA = not appli } \\
\text { *Except where noted } \\
\text { †Except nonmelano }\end{array}$ & $\begin{array}{l}\text { e, SD = standar } \\
\text { erwise. } \\
\text { kin cancers. }\end{array}$ & eviation. & & & & & & \\
\hline
\end{tabular}

Patient response to pharmacists as vaccinators has been positive. ${ }^{30,31}$ For example, Papastergiou and colleagues ${ }^{30}$ found that $92 \%$ of patients who had been vaccinated by a pharmacist were "very satisfied" with the service, with $28 \%$ of respondents overall and $21 \%$ of patients at high risk for influenza complications indicating that they would not have been vaccinated at all if the service had not been available at the pharmacy.

In the current study, demographic predictors of influenza vaccination in a physician's office included living in an urban area or lower-income neighbourhood, identifying as an immigrant, having a chronic disease such as diabetes or hypertension, and being an older adult with a low income or a higher drug cost burden.

Loyalty and familiarity appeared to play an important role in determining the location of influenza vaccination, as shown by the strong association between the current year's and previous year's vaccination location. A patient survey following vaccination by a pharmacist showed that $92 \%$ of respondents 


\section{Research}

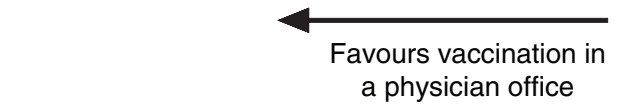

Favours vaccination in

Sex (female) 0.99 (0.99-0.99)

a pharmacy

Rurality

Urban 1.00

Nonmajor urban 1.12 (1.12-1.13)

Rural 1.22 (1.21-1.22)

Neighbourhood income quintile

1 (lowest) 1.00

$21.01(1.00-1.01)$

$31.04(1.03-1.04)$

$41.06(1.06-1.07)$

5 (highest) $1.12(1.11-1.12)$

Month of vaccination

October $2015 \quad 1.00$

November 20151.47 (1.47-1.48)

December $20151.36(1.35-1.37)$

January $20161.21(1.20-1.23)$

February $20161.01(0.99-1.03)$

March $20160.99(0.94-1.03)$

Time since immigration

Not an immigrant 1.00

$<5$ yr 0.87 (0.85-0.88)

$5-9$ yr $0.84(0.82-0.85)$

$\geq 10$ yr $0.80(0.79-0.81)$

Comorbidities

Diabetes $0.84(0.84-0.85)$

Hypertension 0.87 (0.87-0.87)

COPD $0.91(0.90-0.92)$

Asthma 1.01 (1.01-1.02)

CHF 1.00 (0.98-1.02)

AMI 0.96 (0.94-0.97)

Cancer 1.00 (0.99-1.01)

Health care use in previous year

Influenza vaccination in physician office $0.57(0.57-0.57)$

Influenza vaccination in community pharmacy 2.19 (2.18-2.20)

Hospital admission 0.84 (0.83-0.85)

Emergency department visit 1.02 (1.02-1.02)

Home care use 1.10 (1.08-1.11)

No. of physician office visits $0.99(0.99-0.99)$

Periodic health examination 1.01 (1.00-1.02)

\section{Previous pharmacist service}

Pharmacist service in previous year 1.07 (1.06-1.08)

Pharmacist service on day of vaccination 1.43 (1.40-1.45)

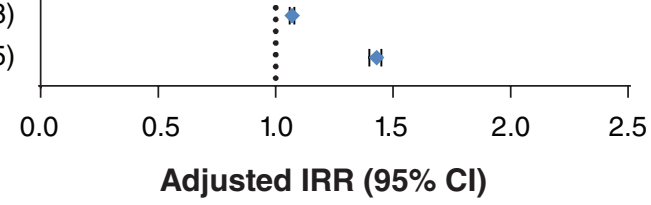

Figure 1: Adjusted incidence rate ratios (IRRs) for being vaccinated in a physician's office versus a community pharmacy for patients aged 65 years or less. Note: $\mathrm{AMI}=$ acute myocardial infarction, $\mathrm{CHF}=$ congestive heart failure, $\mathrm{Cl}=$ confidence interval, $\mathrm{COPD}=$ chronic obstructive pulmonary disease. 
Rurality

Neighbourhood income quintile

Month of vaccination

Comorbidities

Health care use in past year

Influenza vaccination in physician office $0.56(0.56-0.57)$ Influenza vaccination in community pharmacy $2.37(2.35-2.39)$

Hospital admission 1.08 (1.06-1.09)

Emergency department visit 1.01 (1.01-1.02)

Home care use $0.98(0.97-0.99)$

No. of physician office visits $0.99(0.99-0.99)$

Periodic health examination 1.03 (1.02-1.04)

\section{Previous pharmacist service}

No. of unique prescription medications in previous year $1.03(1.03-1.03)$

Total cost of prescription medications in previous year $<\$ 500 \quad 1.00$

$\$ 500-\$ 9990.91(0.90-0.92)$

$\$ 1000-\$ 19990.86(0.85-0.87)$

$\$ 2000-\$ 29990.82(0.81-0.83)$

$\$ 3000-\$ 39990.78(0.77-0.79)$

$\geq \$ 4000 \quad 0.80(0.79-0.81)$

Pharmacist service in previous year $1.01(1.00-1.02)$

Pharmacist service on day of vaccination 1.55 (1.53-1.58)
Nonmajor urban 1.14 (1.13-1.14)

November $20151.52(1.51-1.53)$

January 2016 1.23 (1.21-1.26)

ebruary $20161.07(1.02-1.13)$

Not an immigrant 1.00

< 5 yr $0.69(0.65-0.74)$ $\geq 10$ yr $0.71(0.70-0.72)$

)

(1.07)

Low income $0.90(0.89-0.91)$

00

0)

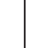

Hypertension $0.89(0.88-0.89)$

COPD $0.96(0.95-0.97)$

CHF $0.95(0.94-0.96)$

AMI 0.98 (0.97-0.99)

5)

Favours vaccination in a physician office
Favours vaccination in a pharmacy 
would receive their next influenza vaccine at a pharmacy. ${ }^{30}$ Interestingly, physician office visits and periodic physician health examinations within the prior year were not predictive of vaccination in a physician's office, and receipt of pharmacist services in the previous year was a weak predictor of pharmacist administration of influenza vaccine. Although infrequent (less than $2 \%$ of patients), receiving another pharmacist service on the day of vaccination was highly associated with influenza vaccination at a pharmacy. This may occur as a result of pharmacists' recommending the influenza vaccine during an activity such as a medication review or using the influenza vaccine opportunity to inquire about medication use, leading to provision of another pharmacist service.

\section{Limitations}

Ontario residents can get vaccinated in locations other than physician offices and pharmacies, such as public health and long-term care facilities and workplaces. Vaccination data from these locations are not collected at the individual patient level (not linkable to ICES demographic or health data) and, therefore, are not included in this study. Errors in the billing data are also a possibility. The covariates related to prescription drug claims are limited to people aged 65 years or more, and, thus, predictive status is unknown for those aged less than 65 years. In determining the difference between influenza seasons, we did not use a multivariable model as the samples were not independent, with many of the same people in both influenza seasons. In addition, the large sample meant that small differences between seasons were statistically significant; instead, we used our clinical judgment to determine where differences occurred between influenza seasons. Finally, in Ontario, pharmacists cannot vaccinate children less than 5 years of age, so comparative data for this age group were not available.

\section{Conclusion}

For the 2013/14 and 2015/16 influenza seasons, the influenza vaccine was administered more frequently in physician offices than in community pharmacies, but the proportion of patients vaccinated in community pharmacies increased between the 2 periods. Living in smaller communities, living in the highest income quintile neighbourhoods and receiving a pharmacist service on the same day as the vaccination were all predictive of being vaccinated in a pharmacy, whereas identifying as an immigrant and the presence of certain chronic health conditions (diabetes and hypertension) were associated with vaccination in a physician's office, regardless of age group. The location of the previous year's vaccination (whether physician's office or pharmacy) was a strong predictor of the vaccine provider for the current influenza season. To further increase influenza vaccine coverage, health care providers can use this information to target patients they are more likely to vaccinate and to identify mechanisms to promote vaccination to those they are less likely to vaccinate. This information also represents an opportunity for physicians and pharmacists to encourage patients to take advantage of the availability of influenza vaccine across various settings, to best align with their preferences and encourage uptake.

\section{References}

1. National Advisory Committee on Immunization (NACI): Canadian immunization guide chapter on influenza and statement on seasonal influenza vaccine for 2018 2019. Advisory Committee Statement. Ottawa: Public Health Agency of Canada; 2018.

2. Schanzer DL, Langley JM, Tam TW. Role of influenza and other respiratory viruses in admissions of adults to Canadian hospitals. Influenza Other Respir Viruses 2008;2:1-8.

3. Thompson WW, Shay DK, Weintraub E, et al. Influenza-associated hospitalizations in the United States. FAMA 2004;292:1333-40.

4. Schanzer DL, Tam TW, Langley JM, et al. Influenza-attributable deaths, Canada 1990-1999. Epidemiol Infect 2007;135:1109-16.

5. Li S, Leader S. Economic burden and absenteeism from influenza-like illness in healthy households with children (5-17 years) in the US. Respir Med 2007; 101:1244-50.

6. Molinari NA, Ortega-Sanchez IR, Messonnier ML, et al. The annual impact of seasonal influenza in the US: measuring disease burden and costs. Vaccine 2007; 25:5086-96.

7. Schanzer DL, Zheng H, Gilmore J. Statistical estimates of absenteeism attributable to seasonal and pandemic influenza from the Canadian Labour Force Survey. BMC Infect Dis 2011;11:90.

8. Kwong JC, Stukel TA, Lim J, et al. The effect of universal influenza immunization on mortality and health care use. PLoS Med 2008;5:e211.

9. Kwong JC, Rosella LC, Johansen H. Trends in influenza vaccination in Canada, 1996/1997 to 2005. Health Rep 2007;18:9-19.

10. Buchan SA, Kwong JC. Trends in influenza vaccine coverage and vaccine hesitancy in Canada, 2006/07 to 2013/14: results from cross-sectional survey data. CMA7 Open 2016;4:E455-62.

11. Law MR, Dijkstra A, Douillard JA, et al. Geographic accessibility of community pharmacies in Ontario. Healthc Policy 2011;6:36-46.

12. Pharmacists in Canada: a national survey of Canadians on their perceptions and attitudes towards pharmacists in Canada. Report no 2. Ottawa: Abacus Data; 2015.

13. Drozd EM, Miller L, Johnsrud M. Impact of pharmacist immunization authority on seasonal influenza immunization rates across states. Clin Ther 2017;39: 1563-80.e17.

14. Isenor JE, Killen JL, Billard BA, et al. Impact of pharmacists as immunizers on influenza vaccination coverage in the community-setting in Nova Scotia, Canada: 2013-2015. J Pharm Policy Pract 2016;9:32.

15. Baroy J, Chung D, Frisch R, et al. The impact of pharmacist immunization programs on adult immunization rates: a systematic review and meta-analysis. $\mathcal{F} \mathrm{Am}$ Pharm Assoc (2003) 2016;56:418-26.

16. Buchan SA, Rosella LC, Finkelstein F et al.; Public Health Agency of Canada/ Canadian Institutes of Health Research Influenza Research Network (PCIRN) Program Delivery and Evaluation Group. Impact of pharmacist administration of influenza vaccines on uptake in Canada. CMA7 2017;189:E146-52.

17. Schwartz KL, Jembere N, Campitelli MA, et al. Using physician billing claims from the Ontario Health Insurance Plan to determine individual influenza vaccination status: an updated validation study. CMA7 Open 2016;4:E463-70.

18. Kralj B. Measuring rurality — RIO2008_BASIC: methodology and results. Toronto: Economics Department, Ontario Medical Association; 2009.

19. Finkelstein MM. Ecologic proxies for household income: How well do they work for the analysis of health and health care utilization? Can 7 Public Health 2004;95:90-4.

20. Hux JE, Ivis F, Flintoft V, et al. Diabetes in Ontario: determination of prevalence and incidence using a validated administrative data algorithm. Diabetes Care 2002;25:512-6.

21. Tu K, Campbell NR, Chen ZL, et al. Accuracy of administrative databases in identifying patients with hypertension. Open Med 2007;1:e18-26.

22. Gershon AS, Wang C, Guan J, et al. Identifying individuals with physician diagnosed COPD in health administrative databases. COPD 2009;6:388-94.

23. Gershon AS, Wang C, Guan J, et al. Identifying patients with physiciandiagnosed asthma in health administrative databases. Can Respir $\mathcal{7} 2009 ; 16$ : 183-8.

24. Schultz SE, Rothwell DM, Chen Z, et al. Identifying cases of congestive heart failure from administrative data: a validation study using primary care patient records. Chronic Dis Inj Can 2013;33:160-6.

25. Tu JV, Naylor CD, Austin P. Temporal changes in the outcomes of acute myocardial infarction in Ontario, 1992-1996. CMA7 1999;161:1257-61.

26. Hall S, Schulze K, Groome P, et al. Using cancer registry data for survival studies: the example of the Ontario Cancer Registry. 7 Clin Epidemiol 2006;59: 67-76.

27. Health care professionals: MedsCheck. Toronto: Queen's Printer for Ontario; 2017. Available: http://health.gov.on.ca/en/pro/programs/drugs/medscheck/ medscheck_original.aspx (accessed 2017 Apr. 3).

28. Zou G. A modified Poisson regression approach to prospective studies with binary data. Am 7 Epidemiol 2004;159:702-6.

29. McNutt LA, Wu C, Xue X, et al. Estimating the relative risk in cohort studies and clinical trials of common outcomes. Am F Epidemiol 2003;157:940-3.

30. Papastergiou J, Folkins C, Li W, et al. Community pharmacist-administered influenza immunization improves patient access to vaccination. Can Pharm 7 (Ott) 2014;147:359-65. 
31. Poulose S, Cheriyan E, Cheriyan R, et al. Pharmacist-administered influenza vaccine in a community pharmacy: a patient experience survey. Can Pharm 7 (Ott) 2015;148:64-7.

32. The role of the pharmacist in public health. Policy statement no 200614. Washington: American Public Health Association; 2006. Available: www.apha.org/ policies-and-advocacy/public-health-policy-statements/policy-database/2014/07/ 07/13/05/the-role-of-the-pharmacist-in-public-health (accessed 2017 Apr. 3).

33. Agomo CO. The role of community pharmacists in public health: a scoping review of the literature. 7 Pharm Health Serv Res 2012;3:25-33.

34. Smith M. Pharmacists' role in public and population health. Ann Public Health Res 2014;1:1006.

35. Eades CE, Ferguson JS, O'Carroll RE. Public health in community pharmacy: a systematic review of pharmacist and consumer views. BMC Public Health $2011 ; 11: 582$

36. Immunization authority. Washington: American Pharmacists Association; 2018. Available: www.pharmacist.com/sites/default/files/files/IZ_Authority_012018. pdf (accessed 2018 Feb. 6).

37. Pharmacists' scope of practice in Canada. Ottawa: Canadian Pharmacists Association; 2016. Available: www.pharmacists.ca/cpha-ca/assets/File/pharmacy-in -canada/Scope\%20of\%20Practice\%20in\%20Canada_JAN2016.pdf (accessed 2017 Apr. 3).

Affiliations: School of Pharmacy (Waite, Houle), University of Waterloo, Kitchener, Ont.; Leslie Dan Faculty of Pharmacy (Cadarette, Consiglio), University of Toronto; ICES (Cadarette, Campitelli, Consiglio, Kwong); Department of Family and Community Medicine (Kwong), University of Toronto, Toronto, Ont.

Contributors: Nancy Waite, Jeffrey Kwong, Suzanne Cadarette, Michael Campitelli and Giulia Consiglio conceived and designed the study, and contributed to data interpretation and drafting the manuscript. Michael Campitelli completed the data extraction and analysis. Sherilyn Houle contributed to data interpretation and drafting the manuscript. All of the authors approved the version to be published and agreed to be accountable for all aspects of the work.

Funding: This study was supported by ICES, which is funded by an annual grant from the Ontario Ministry of Health and Long-Term Care, the Ontario Pharmacy Evidence Network (OPEN) and the Government of Ontario.

Acknowledgements: The authors thank Dana Church and Emily Milne for their facilitation of research meetings, data management and conducting literature reviews, Hannah Chung for her assistance with data management and figure development, and Richard Violette for editing a previous version of the manuscript and assistance with graphics.

Disclaimer: This study was supported by ICES, which is funded by an annual grant from the Ontario Ministry of Health and Long-Term Care (MOHLTC). The opinions, results and conclusions reported in this paper are those of the authors and are independent from the funding sources. No endorsement by ICES or the Ontario MOHLTC is intended or should be inferred. Parts of this material are based on data and/or information compiled and provided by the Canadian Institutes of Health Information.

Supplemental information: For reviewer comments and the original submission of this manuscript, please see www.cmajopen.ca/content/7/2/ E421/suppl/DC1. 